\title{
Memory Formation Shaped by Astroglia
}

\author{
Robert Zorec ${ }^{1,2 *}$, Anemari Horvat ${ }^{1}$, Nina Vardjan ${ }^{1,2}$ and Alexei Verkhratsky ${ }^{1,2,3,4,5,6}$ \\ ${ }^{1}$ Laboratory of Neuroendocrinology and Molecular Cell Physiology, Institute of Pathophysiology, Faculty of Medicine, \\ University of Ljubljana, Ljubljana, Slovenia, ${ }^{2}$ Celica Biomedical, Ljubljana, Slovenia, ${ }^{3}$ Faculty of Life Sciences, University of \\ Manchester, Manchester, UK, ${ }^{4}$ Achucarro Center for Neuroscience, Ikerbasque, Basque Foundation for Science, Bilbao, \\ Spain, ${ }^{5}$ Department of Neurosciences, University of the Basque Country, Leioa, Spain, ${ }^{6}$ University of Nizhny Novgorod, \\ Nizhny Novgorod, Russia
}

Astrocytes, the most heterogeneous glial cells in the central nervous system (CNS), execute a multitude of homeostatic functions and contribute to memory formation. Consolidation of synaptic and systemic memory is a prolonged process and hours are required to form long-term memory. In the past, neurons or their parts have been considered to be the exclusive cellular sites of these processes, however, it has now become evident that astrocytes provide an important and essential contribution to memory formation. Astrocytes participate in the morphological remodeling associated with synaptic plasticity, an energy-demanding process that requires mobilization of glycogen, which, in the CNS, is almost exclusively stored in astrocytes. Synaptic remodeling also involves bidirectional astroglial-neuronal communication supported by astroglial receptors and release of gliosignaling molecules. Astroglia exhibit cytoplasmic excitability that engages second messengers, such as $\mathrm{Ca}^{2+}$, for phasic, and cyclic adenosine monophosphate (CAMP), for tonic signal coordination with neuronal processes. The detection of signals by astrocytes and the release of gliosignaling

OPEN ACCESS

Edited by:

Leif Hertz,

China Medical University, China

Reviewed by:

Linda H.Bergersen, University of Oslo, Norway Gertrudis Perea, Instituto Cajal, Spain

${ }^{*}$ Correspondence: Robert Zorec robert.zorec@mf.uni-lj.si

Received: 13 September 2015 Accepted: 28 October 2015 Published: 17 November 2015

Citation:

Zorec $R$, Horvat A, Vardjan N and Verkhratsky A (2015) Memory Formation Shaped by Astroglia. Front. Integr. Neurosci. 9:56. doi: 10.3389/fnint.2015.00056 molecules, in particular by vesicle-based mechanisms, occurs with a significant delay after stimulation, orders of magnitude longer than that present in stimulus-secretion coupling in neurons. These particular arrangements position astrocytes as integrators ideally tuned to support time-dependent memory formation.

Keywords: astroglia, memory, shape, metabolism, signaling

\section{MEMORY FORMATION RESULTS IN ANATOMICAL CHANGES}

Memory is the process of retention and reconstruction of learned (acquired) knowledge. Studies performed in the early 1960s on patients who underwent bilateral medial temporal lobe surgery, recognized the hippocampus as a fundamental region for memory formation (Scoville and Milner, 1957). Subsequently, two distinct memory systems, declarative (explicit) memory for facts and events, for people, places, and objects ("knowing that") and nondeclarative (implicit) memory, the memory for perceptual and motor skills ("knowing how"), have been defined (Dudai and Morris, 2013). Both systems rely on similar, if not identical, mechanisms associated with reinforcement of synaptic transmission, which involve morphological changes at the synapse that outlast memory stabilization (Attardo et al., 2015). This morphology-based mechanism was considered by Cajal (1894), who linked "cerebral gymnastics" (Box 1) with morphological alterations of dendrites and terminals of neurons. 


\section{BOX 1 | Cerebral gymnastics and memory formation}

"Cerebral gymnastics are not capable of improving the organization of the brain by increasing the number of cells, because it is known that the nerve cells after the embryonic period have lost the property of proliferation; but it can be admitted as very probable that mental exercise leads to a greater development of the dendritic apparatus and of the system of axonal collaterals in the most utilized cerebral regions. In this way, associations already established among certain groups of cells would be notably reinforced by means of the multiplication of the small terminal branches of the dendritic appendages and axonal collaterals; but, in addition, completely new intercellular connections could be established thanks to the new formation of [axonal] collaterals and dendrites."

The Cronian Lecture: La fine structure des centres nerveux. Proceedings of the Royal Society of London 55: 444-468, 1984. Translated by DeFelipe J, Jones, E. G. (1988). Cajal on the Cerebral Cortex. New York, NY: Oxford University Press. p. 87.

Contemporary views assume that memory formation, although it is an outcome of a myriad of interactive processes, occurs in the form of molecular events at the level of an individual synaptic connection, which is termed synaptic plasticity. These synaptic changes integrate through multiple synaptic connections involving larger neuronal networks, and are finally expressed at the behavioral level (Kandel et al., 2014).

\section{MEMORY FORMATION AND ASTROCYTE MORPHOLOGY}

Micro-anatomical changes that are part of memory formation are not exclusively related to neurons and their parts, but involve non-neuronal cells, which in many areas of the human brain exceed the number of neurons (Azevedo et al., 2009). These non-neuronal cells include astrocytes, an abundant and arguably the most heterogeneous glial cell type in the central nervous system (CNS). It is generally acknowledged that astroglia actively participate in information processing via cytosolic calcium signals (Verkhratsky et al., 1998; Rusakov et al., 2011).

A single astrocyte is intimately associated with many neurons and with their synaptic contacts. A single rat cortical astrocyte enwraps 4-8 neuronal bodies and 300-600 dendrites (Halassa et al., 2007), and astrocytes are in contact with synapses. In the rat hippocampus, an individual astrocyte can cover (by perisynaptic processes) up to 140,000 synapses (Bushong et al., 2002). Human hippocampal astrocytes are substantially larger and a single human astrocyte may be associated with $\sim 2$ million synapses (Oberheim et al., 2006). Abundant morphological interactions of astrocytic processes with neurons are not restricted to the hippocampus, being a widespread property of CNS tissue.

Close morphological apposition allows astrocytes to receive signals from the synaptic cleft and feedback by releasing their own signaling molecules. Release of many of these molecules occurs through a secretory pathway that uses cytoplasmic vesicles, which store chemical messengers. On stimulation, the vesicle membrane fuses with the plasmalemma, a process termed regulated exocytosis. The role of secretory vesicles in astrocytes was proposed in 1910 when Nageotte (1910) suggested, based on his microscopic observations, that glial cells (astroglia in particular) act as secretory elements in the CNS. This hypothesis has been confirmed experimentally in the last two decades by identifying vesicular release of gliosignaling molecules, which are often termed gliotransmitters (Vesce et al., 1999; Haydon, 2001; Parpura and Zorec, 2010; Zorec et al., 2012). Although there is some skepticism that this mechanism exists in astroglia (Fujita et al., 2014; Sloan and Barres, 2014), bidirectional astrocyte-neuron signaling is well accepted, and it is generally recognized that vesicle-based mechanisms participate in the heterocellular signaling that occurs at a morphofunctional unit known as the tripartite synapse (Araque et al., 1999; Perea et al., 2009). This bidirectional communication is part of the wider gliocrine system (Vardjan and Zorec, 2015), which reflects the secretory role of astrocytes, which release an extensive number of gliosignaling molecules (Verkhratsky et al., in press). These molecules are largely not involved in synaptic processes but rather regulate various brain functions through "volume" transmission (Vardjan and Zorec, 2015; Zorec et al., 2015). Astroglia-derived signaling molecules are secreted into the extracellular space and are transported throughout the tissue parenchyma to distant places in the CNS, likely taking advantage of the glymphatic convective system (Thrane et al., 2014).

During implicit memory consolidation of Pavlovian threat conditioning, astrocytic processes retract from synapses in the lateral amygdala, allowing these synapses to enlarge, suggesting that contact with astroglial processes opposes synapse growth during memory consolidation (Ostroff et al., 2014). In other words, if astrocytic processes enwrap synapses and the latter need to expand during memory formation, astrocytes may hinder this remodeling, demonstrating how astrocytic structural plasticity enables morphological remodeling of synapses associated with memory formation. Under physiological conditions, including reproduction, sensory stimulation, and learning, astrocytes display a remarkable structural plasticity. Distal astrocytic processes can undergo morphological changes in a matter of minutes, thus modifying the geometry and diffusion properties of the extracellular space and relationships with adjacent neuronal elements, especially with synapses. This type of astroglial plasticity has important functional consequences because it modifies extracellular ionic homeostasis and neurotransmission, thus ultimately modulating neuronal function at the cellular and system levels (Oliet and Piet, 2004; Theodosis et al., 2008). The mechanisms responsible for morphological changes in astrocytes are not known, but these may likely involve adrenergic receptors and generation of second messenger cAMP (Vardjan et al., 2014), which are discussed in the following section.

\section{ASTROCYTE MORPHOLOGY, CAMP AND METABOLISM}

Astrocytes are capable of a remarkable morphological plasticity. Astroglial cells in vitro have a flattened polygonal appearance, 
however stimulation of the $\beta$-adrenergic cAMP-dependent signaling cascade results in rapid morphological remodeling with astrocytes assuming a stellate morphology with numerous processes (Shain et al., 1987; Bicknell et al., 1989; Hatton et al., 1991; Shao et al., 1994; Won and Oh, 2000; Gharami and Das, 2004; Vardjan et al., 2014). This remodeling occurs within the time frame of memory consolidation (minutes to hours) and involves cytoskeletal reorganization, including the restructuring of actin filaments, microtubules, and intermediate filaments (Goldman and Abramson, 1990; Safavi-Abbasi et al., 2001). An example of this adrenergic receptor/cAMP-mediated morphological remodeling of astrocytes is shown in Figure 1 (Vardjan et al., 2014). Similar morphological plasticity may take place in vivo in long-term memory formation because noradrenaline (NA), derived from projections of neurons located in the locus ceruleus (LC), operates as a neuromodulator in Hebbian learning (Johansen et al., 2014). Under similar training conditions, changes in astrocytic shape have indeed been observed (Ostroff et al., 2014). Moreover, the existence of structural-functional changes of the astrocyte-neuron interactions during memory processes have been detected (Lavialle et al., 2011; Bernardinelli et al., 2014; Perez-Alvarez et al., 2014).

Tight association between the synaptic membranes and astrocytes is considered essential for homeostatic control of the synaptic cleft, including rapid removal of the neurotransmitter
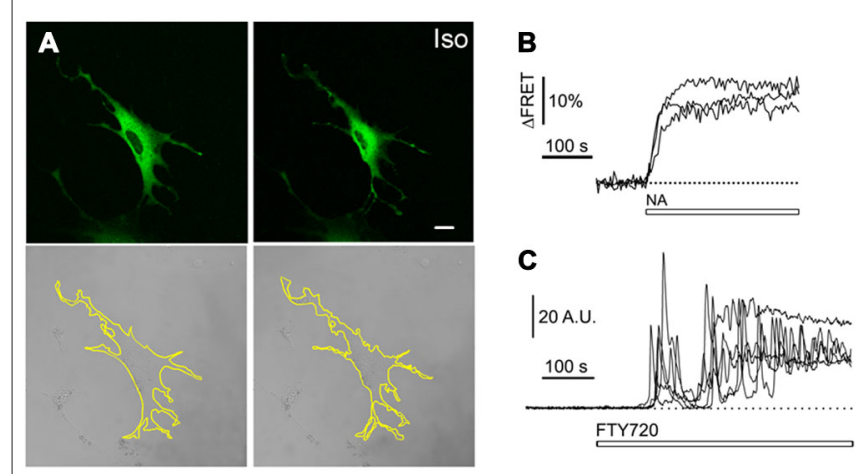

FIGURE 1 | (A) Morphological changes in astrocytes (stellation) induced by the $\beta$-adrenergic receptor ( $\beta$-AR) agonist isoprenaline (Iso), which increases CAMP. Green fluorescing astrocytes transfected with the CAMP nanosensor Epac1-camps (top) and their corresponding differential interference contrast images (bottom) before (left) and after $1 \mu \mathrm{M} \beta$-AR agonist isoprenaline (Iso). Note the thinning and elongation of processes indicating astrocyte stellation. Scale bar represents $20 \mu \mathrm{m}$. Astrocytes were cultured from rat cortex. Modified from Vardjan et al. (2014) with permission. (B) Time course of cytosolic levels of cAMP. Noradrenaline (NA) persistently increases intracellular cAMP levels in astrocytes. Representative time courses of the Epac1-camps (i.e., a Förster resonance energy transfer (FRET)-based cAMP nanosensor) from three cells after the addition of $1 \mu \mathrm{M} N A$. Changes in FRET are expressed as percentages relative to the initial values. (C) Time course of cytosolic levels of $\mathrm{Ca}^{2+}$. The application of fingolimod (FTY720) evokes prolonged transient increases (oscillations). Superimposed time-resolved fluorescence intensity obtained in five cells treated with FTY720 (white bar). The thin dotted line indicates the zero fluorescence level $\left(F_{0}\right)$. Modified from Vardjan and Zorec (2015) with permission. glutamate (Bergles and Jahr, 1997) and potassium from the extracellular space (Orkand et al., 1966; Verkhratsky and Nedergaard, 2014). Thus, retraction of astrocytic membrane from the synapse during memory formation (Ostroff et al., 2014) may facilitate the spillover of neurotransmitter and thus affect synaptic transmission (Rusakov and Kullmann, 1998). At the same time, memory formation is associated with morphological growth of synaptic elements together with enhanced protein synthesis and rearrangement of receptor proteins, all of which increase the energy consumption (Harris et al., 2012).

How energy substrates, needed for adenosine triphosphate (ATP) synthesis, are delivered to synapses where synaptic plasticity takes place is still an open question. A simple assumption would be that pyruvate is provided to the mitochondria by glycolysis within the neuron. However, the morphology of astrocytes, with extensive end feet plastering blood vessels, is well suited to take up glucose from blood and distribute either glucose itself, or pyruvate or lactate derived from glucose, to astrocytic processes surrounding synapses, possibly by diffusion through gap junctions integrating astroglial syncytia (Rouach et al., 2008). In support of this mechanism, diffusion of glucose within astrocytes is relatively rapid (Kreft et al., 2013) and may well support glucose delivery via interconnected astrocytes in situ. Although synapses are the main energy consumers in the brain, glycogen, the only CNS energy storage system, is present mainly, if not exclusively, in astrocytes. Memory consolidation in young chickens requires glycogenolysis (Gibbs et al., 2006; Hertz and Gibbs, 2009). The successful consolidation of memory from short-term to long-term memory requires neuronal NA release (Gibbs et al., 2010). Therefore, it appears that NA, released from neurons, such as those from locus coeruleus, initiates astrocytic morphological changes and activates astroglial energy metabolism. Thus, NA may be considered as an integrator of the metabolism, morphology and function of astrocytes. In the adult operational (i.e., awake) brain, NA is the main signaling molecule that triggers astroglial $\mathrm{Ca}^{2+}$ signaling (Ding et al., 2013), which represents the universal form of glial excitability (Verkhratsky et al., 1998).

\section{ASTROCYTES AS HUBS FOR THE NETWORK RESET SYSTEM}

The LC is the primary source of NA in the CNS. It is localized in the brainstem and projects widely, and is thus able to synchronously activate neural networks in several brain regions. This may be regarded as a functional "reset" for many brain networks (Bouret and Sara, 2005; Sara, 2015). Axons of LC neurons project to the spinal cord, the brain stem, the cerebellum, the hypothalamus, the thalamic relay nuclei, the amygdala, the basal telencephalon, and the cortex, although some cortical areas receive more abundant innervation (Chandler et al., 2014). In all these structures, synchronous activation of LC projections (Bouret and Sara, 2005) leads to coherent and synchronized electrical activity, possibly reflected by gamma waves on an electroencephalogram (Sara, 2015). LC innervation mediates arousal and the sleep-wake cycle, attention 
and memory, behavioral flexibility, behavioral inhibition and stress, cognitive control, emotions, neuroplasticity, posture, and balance (Benarroch, 2009). The effects of NA are mediated through $\alpha$ - and $\beta$-adrenergic receptors ( $\alpha / \beta$ ARs) which are expressed in neurons, microglia, and astrocytes. The ARs were among the first receptors to be causally linked to astroglial $\mathrm{Ca}^{2+}$ signaling (Salm and McCarthy, 1989; Kirischuk et al., 1996). Increases in astroglial $\mathrm{Ca}^{2+}$ were observed in vivo after stimulation of the LC in anesthetized animals (Bekar et al., 2008). In awake animals, stimulation of LC neurons triggered (by activation of $\alpha$-ARs) widespread astroglial $\mathrm{Ca}^{2+}$ signals, which appeared in almost all astrocytes in the field of study (Ding et al., 2013). This synchronous response may represent the means by which neural networks are coordinated. Simultaneously, through activation of $\beta$-ARs, the cAMP-dependent pathways are activated; this in turn instigates rapid degradation of glycogen, which serves as the main energy reserve in the brain (Prebil et al., 2011; Kreft et al., 2012) and initiates morphological plasticity of astrocytes (Vardjan et al., 2014).

\section{VESICULAR RELEASE OF GLIOSIGNALING MOLECULES}

By having secretory vesicles clustered close to the plasma membrane, which is a hallmark of the active zone of the presynaptic terminal, the delay between the incoming stimulus and secretion is minimized, being as short as $100 \mu \mathrm{s}$ (Sabatini and Regehr, 1999). At the same time, vesicle-based release of chemical messengers can exhibit much longer delays in stimulus-secretion coupling. In astrocytes, the mechanism prolonging the time between the arrival of the stimulus and the release of transmitters has been naturally selected, because the maximal speed of regulated exocytosis in astroglia appears much slower than that in neurons (Guček et al., 2012; Neher, 2012; Zorec et al., 2015). Regulated exocytosis also plays a role in many forms of cell-to-cell communication besides release of transmitters, being for example critical for the delivery of transporters, ion channels and antigen presenting molecules to the cell surface (Guček et al., 2012). Vesicular trafficking and release, which have evolved $\sim 3$ billion years ago in arhaea (Spang et al., 2015), is fundamental for signaling and communication within the relatively large eukaryotic cell volume. Communication within large cells could no longer be supported by diffusionbased processes, which provide effective and rapid transport of molecules within the submicron range. Hence the development of subcellular organelles, such as secretory vesicles, presented a solution for the "signaling problem" in the relatively large volume of eukaryotic cells, to which astrocytes belong (Guček et al., 2012).

An ideal approach to monitor the rate-limiting processes of regulated exocytosis in astrocytes at the cellular level is to measure changes in the plasma membrane area, which reflects the fusion of vesicles with the plasma membrane. This can be monitored by measuring membrane capacitance $\left(C_{\mathrm{m}}\right)$, which is linearly related to the membrane area (Neher and Marty, 1982). This technique was used in cultured astrocytes (Kreft et al., 2004) to test the hypothesis that an increase in $\left[\mathrm{Ca}^{2+}\right]_{i}$, after photolysis of caged $\mathrm{Ca}^{2+}$ (Neher and Zucker, 1993), elicits an increase in the whole-cell $C_{\mathrm{m}}$. A half-maximal increase in $C_{\mathrm{m}}$ of these astrocytes was attained at $\sim 27 \mu \mathrm{M}\left[\mathrm{Ca}^{2+}\right]_{\mathrm{i}}$, which is similar to the $\mathrm{Ca}^{2+}$-dependency of regulated exocytosis in various types of neurons, recorded by a similar technique (Heidelberger et al., 1994; Bollmann et al., 2000; Kreft et al., 2003a). In contrast to neurons, however, a rather small, within $100 \mathrm{nM}$, increase in $\left[\mathrm{Ca}^{2+}\right]_{\mathrm{i}}$ from the resting level was sufficient to induce glutamate release from astrocytes, as detected by glutamatergic effects on nearby neurons, used as sniffer cells (Parpura and Haydon, 2000). A similar high-affinity $\mathrm{Ca}^{2+}$ sensing mechanism for vesicular release was reported in pituitary endocrine cells (Kreft et al., 2003b). At present, astrocytes appear to be the slowest secretors of all the excitable mammalian cells investigated thus far. The kinetics of $C_{m}$ increase is at least two orders of magnitude slower than the kinetics of regulated exocytosis recorded by a similar technique in neurons (Kreft et al., 2004; Neher, 2012). The $\mathrm{Ca}^{2+}$. dependent increases in $C_{\mathrm{m}}$ were sensitive to tetanus toxin (which cleaves synaptobrevin 2 and cellubrevin), indicating a soluble $N$-ethyl maleimide-sensitive fusion protein attachment protein receptor and Soluble NSF Attachment Protein Receptor (SNAP)based vesicular mechanism (Kreft et al., 2004).

Why is regulated exocytosis in astrocytes so slow? One reason is the distinct slow kinetics of molecular mechanisms regulating the vesicle membrane-plasmalemma merger. The number of SNARE molecules per vesicle, which is relatively low in astrocytes (Singh et al., 2014), may also contribute to the slow kinetics of regulated exocytosis. Slow delivery of vesicles to the plasma membrane fusion sites may also play a significant role. The vesicle dynamics is an amazingly elaborate system, regulated by increases in $\left[\mathrm{Ca}^{2+}\right]_{\mathrm{i}}$ (Potokar et al., 2013; Vardjan et al., 2015). For example, the complexity of vesicle traffic regulation in astrocytes is characterized by two typical, yet opposing, properties of vesicles that contain peptides, such as atrial natriuretic peptide, and/or ATP, and those that carry amino acids, such as glutamate and D-serine, and are labeled by the glutamate transporter VGLUT1 (Potokar et al., 2005, 2013; Vardjan et al., 2012; Vardjan and Zorec, 2015). Glutamatergic vesicles speed up with an increase in $\left[\mathrm{Ca}^{2+}\right]_{\mathrm{i}}$ (Stenovec, 2007), whereas the same increase in $\left[\mathrm{Ca}^{2+}\right]_{\mathrm{i}}$ slows down peptidergic vesicles and endolysosomes (Potokar et al., 2010).

Glutamatergic and peptidergic vesicles have the capacity to recycle. The mobility of recycling peptidergic vesicles was studied in cultured astrocytes (Potokar et al., 2008) and in intact brain slices (Potokar et al., 2009). At rest, peptidergic vesicles moved faster and more directionally than after the exposure of astrocytes to ionomycin to increase $\left[\mathrm{Ca}^{2+}\right]_{\mathrm{i}}$ (Potokar et al., 2008). The effect of increased $\left[\mathrm{Ca}^{2+}\right]_{i}$ was dramatic; the movement of vesicles was almost halted, with only a jitter associated with random diffusional movement remaining. At least some of the peptidergic vesicles carry ATP and a similar attenuation was observed in their mobility when astrocytes were stimulated (Pangrsic et al., 2007).

What is the physiologic significance of differential mobility of vesicles carrying specific cargo, for example, classic chemical transmitter vs. neuromodulators or neuropeptides? An increase 
or decrease in vesicle mobility may affect the efficiency of vesicle merger with the plasma membrane and the subsequent cargo discharge. It is possible that vesicles engaged in the dichotomous regulation of vesicle traffic exhibit different vesicle sizes, which may determine the nature of vesicle traffic and fusion with the plasmalemma, as was reported for endocrine cells (Flašker et al., 2013). Increased mobility of glutamatergic vesicles (which can quickly refill using VGLUTs) may indicate that they could be discharged at multiple loci at times of increased $\mathrm{Ca}^{2+}$ excitability, resulting in more diffuse signaling as opposed to spatially precise information transfer so characteristic of neuronal synaptic transmission. This speculation seems to be aligned with the ability of astrocytes to modulate synaptic transmission at a long temporal domain and via broad extrasynaptic access sites to neurons.

Impaired astrocytic vesicle traffic has been tentatively associated with intellectual deficiency (ID). Symptoms of ID appear early in life and the disease affects about $2 \%$ of the population. Family studies have demonstrated a relatively large number of X chromosome-linked forms of ID (XLID) with an incidence of about 0.9-1.4 in 1000 males (Turner, 1996). One of the first genes found to be mutated in patients with XLID is GDP dissociation inhibitor 1 (GDI 1; D’Adamo et al., 1998), which encodes for guanine nucleotide dissociation inhibitor ( $\alpha \mathrm{GDI}$ ), a protein physiologically involved in regulating GDP-bound RAB proteins. The identification of GDI1 association with ID suggested that vesicular traffic in neural cells is an important pathway for the development of cognitive functions (D'Adamo et al., 2002; Bianchi et al., 2009). Although the importance of $\alpha$ GDI in neuronal function has been demonstrated, it is unclear whether its role in glia vesicle trafficking contributes to the disease. The $\alpha$ GDI protein regulates the function of RAB GTPases, such as RAB 4 and RAB 5, which have been shown to

\section{REFERENCES}

Araque, A., Parpura, V., Sanzgiri, R. P., and Haydon, P. G. (1999). Tripartite synapses: glia, the unacknowledged partner. Trends Neurosci. 22, 208-215. doi: 10.1016/s0166-2236(98)01349-6

Attardo, A., Fitzgerald, J. E., and Schnitzer, M. J. (2015). Impermanence of dendritic spines in live adult CA1 hippocampus. Nature 523, 592-596. doi: 10. 1038/nature14467

Azevedo, F. A., Carvalho, L. R., Grinberg, L. T., Farfel, J. M., Ferretti, R. E., Leite, R. E., et al. (2009). Equal numbers of neuronal and nonneuronal cells make the human brain an isometrically scaled-up primate brain. J. Comp. Neurol. 513, 532-541. doi: 10.3410/f.1162921.623548

Bekar, L. K., He, W., and Nedergaard, M. (2008). Locus coeruleus alpha-adrenergic-mediated activation of cortical astrocytes in vivo. Cereb. Cortex 18, 2789-2795. doi: 10.1093/cercor/bhn040

Benarroch, E. E. (2009). The locus ceruleus norepinephrine system: functional organization and potential clinical significance. Neurology 73, 1699-1704. doi: 10.1212/wnl.0b013e3181c2937c

Bergles, D. E., and Jahr, C. E. (1997). Synaptic activation of glutamate transporters in hippocampal astrocytes. Neuron 19, 1297-1308. doi: 10.1016/s08966273(00)80420-1

Bernardinelli, Y., Randall, J., Janett, E., Nikonenko, I., König, S., Jones, E. V., et al. (2014). Activity-dependent structural plasticity of perisynaptic astrocytic domains promotes excitatory synapse stability. Curr. Biol. 24, 1679-1688. doi: 10.1016/j.cub.2014.06.025 regulate vesicle dynamics in astrocytes (Potokar et al., 2012), and it is likely that impaired vesicle traffic in astrocytes contributes to ID, which is linked to impaired cognitive processes involving memory formation.

\section{CONCLUSION}

Astroglial cells control homeostasis in the CNS to support many processes including memory formation. Astrocytes contribute to memory as signaling hubs and as structures that alter their morphology and recruit energy resources for memory consolidation. Excitation-secretion coupling in astrocytes is loose and this may be of particular importance to support the slowness of the overall memory-related structural dynamics in the CNS.

\section{AUTHOR CONTRIBUTIONS}

RZ, AH, NV, AV wrote the manuscript.

\section{ACKNOWLEDGMENTS}

AV's research was supported by the Alzheimer's Research Trust (UK), by a grant (agreement from August 27, 2013, no. 02.B.49.21.0003) between The Ministry of Education and Science of the Russian Federation and Lobachevsky State University of Nizhny Novgorod, and by a grant from the Russian Scientific Foundation (no. 14-15-00633); AV was also supported by Plan Nacional de I+D+I 2008-2011 and ISCIII-Subdirección General de Evaluación y Fomento de la investigación co-financed by FEDER (grant PI10/02738 to JJR and AV); RZ's work is supported by the Slovenian Research Agency (grant nos. P3 310, J3 4051, J3-6789, J3 6790).

Bianchi, V., Farisello, P., Baldelli, P., Meskenaite, V., Milanese, M., Vecellio, M., et al. (2009). Cognitive impairment in Gdil-deficient mice is associated with altered synaptic vesicle pools and short-term synaptic plasticity and can be corrected by appropriate learning training. Hum. Mol. Genet. 18, 105-117. doi: $10.1093 / \mathrm{hmg} / \mathrm{ddn} 321$

Bicknell, R. J., Luckman, S. M., Inenaga, K., Mason, W. T., and Hatton, G. I. (1989). Beta-adrenergic and opioid receptors on pituicytes cultured from adult rat neurohypophysis: regulation of cell morphology. Brain Res. Bull. 22, 379-388. doi: 10.1016/0361-9230(89)90065-8

Bollmann, J. H., Sakmann, B., and Borst, J. G. (2000). Calcium sensitivity of glutamate release in a calyx-type terminal. Science 289, 953-957. doi: 10. $1126 /$ science.289.5481.953

Bouret, S., and Sara, S. J. (2005). Network reset: a simplified overarching theory of locus coeruleus noradrenaline function. Trends Neurosci. 28, 574-582. doi: 10. 1016/j.tins.2005.09.002

Bushong, E. A., Martone, M. E., Jones, Y. Z., and Ellisman, M. H. (2002) Protoplasmic astrocytes in CA1 stratum radiatum occupy separate anatomical domains. J. Neurosci. 22, 183-192.

Cajal, S. R. (1894). The Croonian lecture: La fine structure de centres nerveux. Proc. R. Soc. Lond. 55, 444-468. doi: 10.1098/rspl.1894. 0063

Chandler, D. J., Gao, W. J., and Waterhouse, B. D. (2014). Heterogeneous organization of the locus coeruleus projections to prefrontal and motor cortices. Proc. Natl. Acad. Sci. U S A 111, 6816-6821. doi: 10.1073/pnas. 1320827111 
D’Adamo, P., Menegon, A., Lo Nigro, C., Grasso, M., Gulisano, M., Tamanini, F., et al. (1998). Mutations in GDI1 are responsible for X-linked non-specific mental retardation. Nat. Genet. 19, 134-139. doi: 10.1093/hmg/7.8.1311

D’Adamo, P., Welzl, H., Papadimitriou, S., Raffaele di Barletta, M., Tiveron, C., Tatangelo, L., et al. (2002). Deletion of the mental retardation gene Gdil impairs associative memory and alters social behavior in mice. Hum. Mol. Genet. 11, 2567-2580. doi: 10.1093/hmg/11.21.2567

Ding, F., O’Donnell, J., Thrane, A. S., Zeppenfeld, D., Kang, H., Xie, L., et al. (2013). $\alpha 1$-Adrenergic receptors mediate coordinated $\mathrm{Ca} 2+$ signaling of cortical astrocytes in awake, behaving mice. Cell Calcium 54, 387-394. doi: 10.1016/j.ceca.2013.09.001

Dudai, Y., and Morris, R. G. (2013). Memorable trends. Neuron 80, 742-750. doi: 10.1016/j.neuron.2013.09.039

Flašker, A., Jorgačevski, J., Calejo, A. I., Kreft, M., and Zorec, R. (2013). Vesicle size determines unitary exocytic properties and their sensitivity to sphingosine. Mol. Cell Endocrinol. 376, 136-147. doi: 10.1016/j.mce.2013.06.012

Fujita, T., Chen, M. J., Li, B., Smith, N. A., Peng, W., Sun, W., et al. (2014). Neuronal transgene expression in dominant-negative SNARE mice. J. Neurosci. 34, 16594-16604. doi: 10.1523/jneurosci.2585-14.2014

Gharami, K., and Das, S. (2004). Delayed but sustained induction of mitogenactivated protein kinase activity is associated with beta-adrenergic receptormediated morphological differentiation of astrocytes. J. Neurochem. 88, 12-22. doi: 10.1046/j.1471-4159.2003.02148.x

Gibbs, M. E., Anderson, D. G., and Hertz, L. (2006). Inhibition of glycogenolysis in astrocytes interrupts memory consolidation in young chickens. Glia 54, 214-222. doi: 10.1002/glia.20377

Gibbs, M. E., Hutchinson, D. S., and Summers, R. J. (2010). Noradrenaline release in the locus coeruleus modulates memory formation and consolidation; roles for $\alpha$ - and $\beta$-adrenergic receptors. Neuroscience 170, 1209-1222. doi: 10.1016/j. neuroscience.2010.07.052

Goldman, J. E., and Abramson, B. (1990). Cyclic AMP-induced shape changes of astrocytes are accompanied by rapid depolymerization of actin. Brain Res. 528, 189-196. doi: 10.1016/0006-8993(90)91657-3

Guček, A., Vardjan, N., Zorec, R. (2012). Exocytosis in astrocytes: transmitter release and membrane signal regulation. Neurochem. Res. 37, 2351-2363. doi: 10.1007/s11064-012-0773-6

Halassa, M. M., Fellin, T., Takano, H., Dong, J. H., and Haydon, P. G. (2007). Synaptic islands defined by the territory of a single astrocyte. J. Neurosci. 27, 6473-6477. doi: 10.1523/jneurosci.1419-07.2007

Harris, J. J., Jolivet, R., and Attwell, D. (2012). Synaptic energy use and supply. Neuron 75, 762-777. doi: 10.1016/j.neuron.2012.08.019

Hatton, G. I., Luckman, S. M., and Bicknell, R. J. (1991). Adrenalin activation of beta 2-adrenoceptors stimulates morphological changes in astrocytes (pituicytes) cultured from adult rat neurohypophyses. Brain Res Bull 26, 765-769. doi: 10.1016/0361-9230(91)90173-h

Haydon, P. G. (2001). GLIA: listening and talking to the synapse. Nat. Rev. Neurosci. 2, 185-193. doi: 10.1038/35058528

Heidelberger, R., Heinemann, C., Neher, E., and Matthews, G. (1994). Calcium dependence of the rate of exocytosis in a synaptic terminal. Nature 371, 513-515. doi: 10.1038/371513a0

Hertz, L., and Gibbs, M. E. (2009). What learning in day-old chickens can teach a neurochemist: focus on astrocyte metabolism. J. Neurochem. 109, 10-16. doi: 10.1111/j.1471-4159.2009.05939.x

Johansen, J. P., Diaz-Mataix, L., Hamanaka, H., Ozawa, T., Ycu, E., Koivumaa, J., et al. (2014). Hebbian and neuromodulatory mechanisms interact to trigger associative memory formation. Proc. Natl. Acad. Sci. U S A 111, E5584-E5592. doi: 10.1073/pnas.1421304111

Kandel, E. R., Dudai, Y., and Mayford, M. R. (2014). The molecular and systems biology of memory. Cell 157, 163-186. doi: 10.1016/j.cell.2014. 03.001

Kirischuk, S., Tuschick, S., Verkhratsky, A., and Kettenmann, H. (1996). Calcium signalling in mouse Bergmann glial cells mediated by alphal-adrenoreceptors and H1 histamine receptors. Eur. J. Neurosci. 8, 1198-1208. doi: 10.1111/j.14609568.1996.tb01288.x

Kreft, M., Bak, L. K., Waagepetersen, H. S., and Schousboe, A. (2012). Aspects of astrocyte energy metabolism, amino acid neurotransmitter homoeostasis and metabolic compartmentation. ASN Neuro. 4:e00086. doi: 10.1042/an20 120007
Kreft, M., Krizaj, D., Grilc, S., Zorec, R. (2003a). Properties of exocytotic response in vertebrate photoreceptors. J. Neurophysiol. 90, 218-225. doi: 10.1152/jn. 01025.2002

Kreft, M., Kuster, V., Grilc, S., Rupnik, M., Milisav, I., and Zorec, R. (2003b). Synaptotagmin I increases the probability of vesicle fusion at low $[\mathrm{Ca} 2+]$ in pituitary cells. Am. J. Physiol. Cell Physiol. 284, C547-C554. doi: 10 1152/ajpcell.00333.2002

Kreft, M., Lukšič, M., Zorec, T. M., Prebil, M., and Zorec, R. (2013). Diffusion of D-glucose measured in the cytosol of a single astrocyte. Cell. Mol. Life Sci. 70, 1483-1492. doi: 10.1007/s00018-012-1219-7

Kreft, M., Stenovec, M., Rupnik, M., Grilc, S., Krzan, M., Potokar, M., et al. (2004). Properties of $\mathrm{Ca}(2+)$-dependent exocytosis in cultured astrocytes. Glia 46, 437-445. doi: 10.1002/glia.20018

Lavialle, M., Aumann, G., Anlauf, E., Pröls, F., Arpin, M., and Derouiche, A. (2011). Structural plasticity of perisynaptic astrocyte processes involves ezrin and metabotropic glutamate receptors. Proc. Natl. Acad. Sci. U S A 108, 12915-12919. doi: 10.1073/pnas.1100957108

Nageotte, J. (1910). Phenomenes de secretion dans le protoplasma des cellules nevrogliques de la substance grise. C R Soc. Biol. (Paris) 68, 1068-1069.

Neher, E. (2012). Introduction: regulated exocytosis. Cell Calcium 52, 196-198. doi: 10.1016/j.ceca.2012.04.013

Neher, E., and Marty, A. (1982). Discrete changes of cell membrane capacitance observed under conditions of enhanced secretion in bovine adrenal chromaffin cells. Proc. Natl. Acad. Sci. U S A 79, 6712-6716. doi: 10.1073/pnas.79. 21.6712

Neher, E., and Zucker, R. S. (1993). Multiple calcium-dependent processes related to secretion in bovine chromaffin cells. Neuron 10, 21-30. doi: 10.1016/08966273(93)90238-m

Oberheim, N. A., Wang, X., Goldman, S., and Nedergaard, M. (2006). Astrocytic complexity distinguishes the human brain. Trends Neurosci. 29, 547-553. doi: 10.1016/j.tins.2006.08.004

Oliet, S. H., and Piet, R. (2004). Anatomical remodelling of the supraoptic nucleus: changes in synaptic and extrasynaptic transmission. J. Neuroendocrinol. 16, 303-307. doi: 10.1111/j.0953-8194.2004.01159.x

Orkand, R. K., Nicholls, J. G., and Kuffler, S. W. (1966). Effect of nerve impulses on the membrane potential of glial cells in the central nervous system of amphibia. J. Neurophysiol. 29, 788-806.

Ostroff, L. E., Manzur, M. K., Cain, C. K., and Ledoux, J. E. (2014). Synapses lacking astrocyte appear in the amygdala during consolidation of pavlovian threat conditioning. J. Comp. Neurol. 522, 2152-2163. doi: 10.1002/cne. 23523

Pangrsic, T., Potokar, M., Stenovec, M., Kreft, M., Fabbretti, E., Nistri, A., et al. (2007). Exocytotic release of ATP from cultured astrocytes. J. Biol. Chem. 282, 28749-28758. doi: 10.1074/jbc.m700290200

Parpura, V., and Haydon, P. G. (2000). Physiological astrocytic calcium levels stimulate glutamate release to modulate adjacent neurons. Proc. Natl. Acad. Sci. U S A 97, 8629-8634. doi: 10.1073/pnas.97.15.8629

Parpura, V., and Zorec, R. (2010). Gliotransmission: Exocytotic release from astrocytes. Brain Res. Rev. 63, 83-92. doi: 10.1016/j.brainresrev.2009.11.008

Perea, G., Navarrete, M., and Araque, A. (2009). Tripartite synapses: astrocytes process and control synaptic information. Trends Neurosci. 32, 421-431. doi: 10.1016/j.tins.2009.05.001

Perez-Alvarez, A., Navarrete, M., Covelo, A., Martin, E. D., and Araque, A. (2014). Structural and functional plasticity of astrocyte processes and dendritic spine interactions. J. Neurosci. 34, 12738-12744. doi: 10.1523/jneurosci.3913-14.2014

Potokar, M., Kreft, M., Lee, S. Y., Takano, H., Haydon, P. G., and Zorec, R. (2009). Trafficking of astrocytic vesicles in hippocampal slices. Biochem. Biophys. Res. Commun. 390, 1192-1196. doi: 10.1016/j.bbrc.2009.10.119

Potokar, M., Kreft, M., Pangrsic, T., and Zorec, R. (2005). Vesicle mobility studied in cultured astrocytes. Biochem. Biophys. Res. Commun. 329, 678-683. doi: 10. 1016/j.bbrc.2005.02.030

Potokar, M., Lacovich, V., Chowdhury, H. H., Kreft, M., and Zorec, R. (2012). Rab4 and Rab5 GTPase are required for directional mobility of endocytic vesicles in astrocytes. Glia 60, 594-604. doi: 10.1002/glia.22293

Potokar, M., Stenovec, M., Gabrijel, M., Li, L., Kreft, M., Grilc, S., et al. (2010). Intermediate filaments attenuate stimulation-dependent mobility of endosomes/lysosomes in astrocytes. Glia 58, 1208-1219. doi: 10.1002/glia. 21000 
Potokar, M., Stenovec, M., Kreft, M., Kreft, M. E., and Zorec, R. (2008). Stimulation inhibits the mobility of recycling peptidergic vesicles in astrocytes. Glia 56, 135-144. doi: 10.1002/glia.20597

Potokar, M., Vardjan, N., Stenovec, M., Gabrijel, M., Trkov, S., Jorgačevski, J., et al. (2013). Astrocytic vesicle mobility in health and disease. Int. J. Mol. Sci. 14, 11238-11258. doi: 10.3390/ijms140611238

Prebil, M., Vardjan, N., Jensen, J., Zorec, R., and Kreft, M. (2011). Dynamic monitoring of cytosolic glucose in single astrocytes. Glia 59, 903-913. doi: 10 . 1002/glia.21161

Rouach, N., Koulakoff, A., Abudara, V., Willecke, K., and Giaume, C. (2008). Astroglial metabolic networks sustain hippocampal synaptic transmission. Science 322, 1551-1555. doi: 10.1126/science.1164022

Rusakov, D. A., and Kullmann, D. M. (1998). Extrasynaptic glutamate diffusion in the hippocampus: ultrastructural constraints, uptake and receptor activation. J. Neurosci. 18, 3158-3170.

Rusakov, D. A., Zheng, K., and Henneberger, C. (2011). Astrocytes as regulators of synaptic function: a quest for the Ca2+ master key. Neuroscientist 17, 513-523. doi: 10.1177/1073858410387304

Sabatini, B. L., and Regehr, W. G. (1999). Timing of synaptic transmission. Annu. Rev. Physiol. 61, 521-542.

Safavi-Abbasi, S., Wolff, J. R., and Missler, M. (2001). Rapid morphological changes in astrocytes are accompanied by redistribution but not by quantitative changes of cytoskeletal proteins. Glia 36, 102-115. doi: 10.1002/glia. 1099

Salm, A. K., and McCarthy, K. D. (1989). Expression of beta-adrenergic receptors by astrocytes isolated from adult rat cortex. Glia 2, 346-352. doi: 10.1002/glia. 440020507

Sara, S. J. (2015). Locus Coeruleus in time with the making of memories. Curr. Opin. Neurobiol. 35, 87-94. doi: 10.1016/j.conb.2015.07.004

Scoville, W. B., and Milner, B. (1957). Loss of recent memory after bilateral hippocampal lesions. J. Neurol. Neurosurg. Psychiatry. 20, 11-21.

Shain, W., Forman, D. S., Madelian, V., and Turner, J. N. (1987). Morphology of astroglial cells is controlled by beta-adrenergic receptors. J. Cell Biol. 105, 2307-2314. doi: 10.1083/jcb.105.5.2307

Shao, Y., Enkvist, M. O., and McCarthy, K. D. (1994). Glutamate blocks astroglial stellation: effect of glutamate uptake and volume changes. Glia 11, 1-10. doi: 10. 1002/glia.440110103

Singh, P., Jorgačevski, J., Kreft, M., Grubišic, V., Stout, R. F., Potokar, M., et al. (2014). Single-vesicle architecture of synaptobrevin2 in astrocytes. Nat. Commun. 5:3780. doi: 10.1038/ncomms4780

Sloan, S. A., and Barres, B. A. (2014). Looks can be deceiving: reconsidering the evidence for gliotransmission. Neuron 84, 1112-1115. doi: 10.1016/j.neuron. 2014.12.003

Spang, A., Saw, J. H., Jørgensen, S. L., Zaremba-Niedzwiedzka, K., Martijn, J., Lind, A. E., et al. (2015). Complex archaea that bridge the gap between prokaryotes and eukaryotes. Nature 521, 173-179. doi: 10.3410/f.725469610. 793509469

Stenovec, M. (2007). Ca2+-dependent mobility of vesicles capturing antiVGLUT1 antibodies. Exp. Cell Res. 313, 3809-3818. doi: 10.1016/j.yexcr.2007. 08.020

Theodosis, D. T., Poulain, D. A., and Oliet, S. H. (2008). Activitydependent structural and functional plasticity of astrocyte-neuron interactions. Physiol. Rev. 88, 983-1008. doi: 10.1152/physrev.000 36.2007

Thrane, A. S., Rangroo Thrane, V., and Nedergaard, M. (2014). Drowning stars: reassessing the role of astrocytes in brain edema. Trends Neurosci. 37, 620-628. doi: 10.1016/j.tins.2014.08.010

Turner, G. (1996). Finding genes on the X chromosome by which homo may have become sapiens. Am. J. Hum. Genet. 58, 1109-1110.

Vardjan, N., Gabrijel, M., Potokar, M., Svajger, U., Kreft, M., Jeras, M., et al. (2012). IFN- $\gamma$-induced increase in the mobility of MHC class II compartments in astrocytes depends on intermediate filaments. J. Neuroinflammation 9:144. doi: 10.1186/1742-2094-9-144

Vardjan, N., Kreft, M., and Zorec, R. (2014). Dynamics of $\beta$-adrenergic/cAMP signaling and morphological changes in cultured astrocytes. Glia 62, 566-579. doi: doi: 10.1002/glia.22626

Vardjan, N., Verkhratsky, A., Zorec, R. (2015). Pathologic potential of astrocytic vesicle traffic: new targets to treat neurologic diseases? Cell Transplant. 24, 599-612. doi: 10.3727/096368915X687750

Vardjan, N., and Zorec, R. (2015). Excitable astrocytes: $\mathrm{Ca}^{2+}{ }_{-}$and cAMPregulated exocytosis. Neurochem. Res. doi: 10.1007/s11064-015-1545-x [Epub ahead of print].

Verkhratsky, A., Matteoli, M., Mothet, J.-P., Parpura, V., and Zorec, R. (in press). Astrocytes as secretory cells of the central nervous system: idiosyncrasies of vesicular secretion. EMBO J. (in press)

Verkhratsky, A., and Nedergaard, M. (2014). Astroglial cradle in the life of the synapse. Philos. Trans. R. Soc. Lond. B. Biol. Sci. 369:20130595. doi: 10. 1098/rstb.2013.0595

Verkhratsky, A., Orkand, R. K., and Kettenmann, H. (1998). Glial calcium: homeostasis and signaling function. Physiol. Rev. 78, 99-141.

Vesce, S., Bezzi, P., and Volterra, A. (1999). The active role of astrocytes in synaptic transmission. Cell. Mol. Life Sci. 56, 991-1000. doi: 10.1007/s000180050488

Won, C. L., and Oh, Y. S. (2000). cAMP-induced stellation in primary astrocyte cultures with regional heterogeneity. Brain Res. 887, 250-258. doi: 10. 1016/s0006-8993(00)02922-x

Zorec, R., Araque, A., Carmignoto, G., Haydon, P. G., Verkhratsky, A., and Parpura, V. (2012). Astroglial excitability and gliotransmission: an appraisal of $\mathrm{Ca} 2+$ as a signalling route. ASN Neuro. 4:e00080. doi: 10.1042/an201 10061

Zorec, R., Verkhratsky, A., Rodríguez, J. J., Parpura, V. (2015). Astrocytic vesicles and gliotransmitters: slowness of vesicular release and synaptobrevin2-laden vesicle nanoarchitecture. Neuroscience doi: 10.1016/j.neuroscience.2015.02.033 [Epub ahead of print].

Conflict of Interest Statement: The authors declare that the research was conducted in the absence of any commercial or financial relationships that could be construed as a potential conflict of interest.

Copyright () 2015 Zorec, Horvat, Vardjan and Verkhratsky. This is an open-access article distributed under the terms of the Creative Commons Attribution License (CC $B Y)$. The use, distribution and reproduction in other forums is permitted, provided the original author(s) or licensor are credited and that the original publication in this journal is cited, in accordance with accepted academic practice. No use, distribution or reproduction is permitted which does not comply with these terms. 